\title{
Two E-selectin ligands, BST-2 and LGALS3BP, predict metastasis and poor survival of ER-negative breast cancer
}

\author{
NATALIE WOODMAN $^{1}$, SARAH E. PINDER ${ }^{1}$, VIRGINIA TAJADURA ${ }^{2}$, XUEFEN LE BOURHIS $^{3}$, \\ CHERYL GILLETT $^{1}$, PHILIPPE DELANNOY ${ }^{4}$, JOY M. BURCHELL ${ }^{2}$ and SYLVAIN JULIEN ${ }^{3,4}$ \\ ${ }^{1}$ Breast Research Pathology, ${ }^{2}$ Breast Cancer Biology, Research Oncology, King's College London, Guy's Hospital, \\ London, UK; ${ }^{3}$ University of Lille, INSERM, U908 - CPAC, Cell Plasticity and Cancer; ${ }^{4}$ University of Lille, \\ CNRS, UMR 8576 - UGSF, Unit of Structural and Functional Glycobiology, Lille, Villeneuve d'Ascq, France
}

Received October 5, 2015; Accepted January 11, 2016

DOI: $10.3892 /$ ijo.2016.3521

\begin{abstract}
Distant metastases account for the majority of cancer-related deaths in breast cancer. The rate and site of metastasis differ between estrogen receptor (ER)-negative and ER-positive tumours, and metastatic fate can be very diverse even within the ER-negative group. Characterisation of new pro-metastatic markers may help to identify patients with higher risk and improve their care accordingly. Selectin ligands aberrantly expressed by cancer cells promote metastasis by enabling interaction between circulating tumour cells and endothelial cells in distant organs. These ligands consist in carbohydrate molecules, such as sialyl-Lewis $\mathrm{x}$ antigen $\left(\mathrm{sLe}^{\mathrm{x}}\right)$, borne by glycoproteins or glycolipids on the cancer cell surface. We have previously demonstrated that the molecular scaffold presenting sLe ${ }^{\mathrm{x}}$ to selectins (e.g. glycolipid vs. glycoproteins) was crucial for these interactions to occur. Moreover, we reported that detection of $s \mathrm{Se}^{\mathrm{x}}$ alone in breast carcinomas was only of limited prognostic value. However, since $\mathrm{sLe}^{\mathrm{x}}$ was found to be carried by several glycoproteins in cancer cells, we hypothesized that the combination of the carbohydrate with its carriers could be more relevant than each marker independently. In this study, we addressed this question by analysing $\mathrm{sLe}^{\mathrm{x}}$ expression together with two glycoproteins (BST-2 and LGALS3BP), shown to interact with E-selectin in a carbohydrate-dependent manner, in a cohort of 249 invasive
\end{abstract}

Correspondence to: Dr Sylvain Julien, Cell Plasticity and Cancer, INSERM U908, Batiment SN3, Université, Lille 1, 59655 Villeneuve d'Ascq, France

E-mail: sylvain.julien@univ-lille1.fr

Abbreviations: BCSS, breast cancer specific survival; BST-2, bone marrow stromal antigen 2; DM, distant metastasis; ER, estrogen receptor; HUVECs, human umbilical vein endothelial cells; LGALS3BP, galectin-3-binding protein; LN, lymph node; mAb, monoclonal antibody; NHS, national health service; PR, progesterone receptor; $\mathrm{sLe}^{\mathrm{x}}$, sialyl-Lewis $\mathrm{x}$ antigen; TMA, tissue microarray

Key words: breast cancer, sialyl-Lewis x, BST-2, LGALS3BP, metastasis breast cancers. We found both glycoproteins to be associated with distant metastasis risk and poorer survival. Importantly, concomitant high expression of BST-2 with sLe ${ }^{\mathrm{x}}$ defined a subgroup of patients with ER-negative tumours displaying higher risks of liver and brain metastasis and a 3-fold decreased survival rate.

\section{Introduction}

The 5-year overall survival of breast cancer patients with distant metastasis is $23.4 \%$ (http://seer.cancer.gov/ for details see ref. 1) and once detected, metastatic breast cancer is incurable. Distant metastases arise from circulating cancer cells that migrate from the blood stream to colonise a distant organ (extravasation) (2). Specific inhibition of cancer cell extravasation would therefore potentially lead to a decrease in the incidence of metastasis. Thus, delineating the molecular mechanisms involved in this process is one of the crucial challenges for breast cancer treatment.

One such mechanism is the interaction between sialylLewis $\mathrm{x}\left(\mathrm{sLe}^{\mathrm{x}}\right)$ antigen expressed by cancer cells and the selectins expressed by endothelial or circulating immune cells (3). There is a compelling body of evidence that $\mathrm{sLe}^{\mathrm{x}} /$ selectin interaction is involved in metastatic progression in several types of solid tumours including gastric (4), lung (5) and prostate (6) cancers. However, the relationship in breast cancer metastasis remains controversial (7).

We have previously reported that $\mathrm{sLe}^{\mathrm{x}}$ was over-expressed in estrogen receptor (ER)-negative breast tumours compared to ER-positive ones. Although ER-negative cancers are known to typically be of higher grade and intrinsically more aggressive and more often develop metastatic foci, we found no evidence that $\mathrm{sLe}^{\mathrm{x}}$ was correlated with metastatic behaviour either in the ER-negative or the ER-positive group (7).

This lack of association led us to question the context of expression of $\mathrm{sLe}^{\mathrm{x}}$ in breast cancer cells, asking whether the scaffold carrying $\mathrm{sLe}^{\mathrm{x}}$ (e.g. glycosphingolipids or specific glycoproteins) influenced its role in metastasis. Indeed, we reported that rolling on endothelial cells was more efficient when $\mathrm{SLe}^{\mathrm{x}}$ was carried by glycoproteins rather than glycolipids (7). However, sLe ${ }^{\mathrm{x}}$ was found to be carried by several membrane bound glycoproteins in a breast cancer cell line that 
displayed selectin-dependent rolling on endothelial lining. We identified two of these glycoproteins as tetherin, also known as bone marrow stromal antigen 2 (BST-2), and the galectin3-binding protein (also named MAC-2BP) encoded by the $L G A L S 3 B P$ gene (7). Subsequently, Shirure et al have shown that MAC-2BP carrying $\mathrm{sLe}^{\mathrm{x}}$ was functionally involved in ZR-75-1 rolling on HUVECs cultured as monolayer (8).

In the present study, we assessed the expression of $\mathrm{sLe}^{\mathrm{x}}$, BST-2 and LGALS3BP in a cohort of 249 invasive breast cancer patients. We investigated whether the combination of $\mathrm{sLe}^{\mathrm{x}}$ with one or other of its known carriers has a bearing on the prognostic value of $\mathrm{sLe}^{\mathrm{x}}$.

\section{Materials and methods}

Human samples. The samples used in the study were provided by the King's Health Partners Cancer Biobank under their generic ethics approval from National Research Ethics Service, Committee East of England-Cambridge East, reference 12/EE/0493. Under this approval the Biobank are also able to provide pseudo-anonymised samples for research without informed consent if they were collected before September 2006. All tissue samples used in the study were collected prior to Human Tissue Act 2004.

Tissue microarray (TMA) construction and analysis. Formalin-fixed paraffin wax embedded tissue from consecutive cases of invasive breast carcinoma dating from 1990 to 1995 ( $\mathrm{n}=400)$ were selected from the King's Health Partners Cancer Biobank. Clinical data, including date and site of metastatic recurrence, were collected and validated for each sample. From each block 0.6-mm diameter cores were marked on haematoxylin and eosin-stained slides and the invasive cancer subsequently sampled using the Beecher TMArrayer (Wisconsin, MA, USA) and placed into replicate, 100 core TMA blocks. Sections from two duplicate TMA blocks were cut at $3 \mu \mathrm{m}$ and dried overnight at $37^{\circ} \mathrm{C}$. Sections were baked for $2 \mathrm{~h}$ at $60^{\circ} \mathrm{C}$, blocked using $10 \%$ bovine serum albumin in PBS and stained with anti-sLe ${ }^{\mathrm{x}}$ monoclonal antibody (mAb) HECA-452 (7) (BD Biosciences, Oxford, UK) at a concentration of $1 \mu \mathrm{g} \cdot \mathrm{ml}^{-1}$, anti-LGALS3PB mAb 6B7 (Novus Biologicals, Cambridge, UK) at a concentration of $0.2 \mu \mathrm{g} . \mathrm{ml}^{-1}$, or anti-BST-2 polyclonal antibody (9) (Novus Biologicals) at a concentration of $0.2 \mu \mathrm{g} \cdot \mathrm{ml}^{-1}$. The staining was performed using a Ventana Ultra automat (Roche, Rotkreuz, Switzerland) running on Program U33. Primary antibodies were incubated for $32 \mathrm{~min}$ on slides, without heating, followed with appropriate secondary and tertiary reagents (UltraView universal DAB Detection kit; Dako, Ely, UK). Staining conditions were optimised for each antibody using a panel of pellets of breast cancer cell lines that were formalin-fixed and paraffinembedded (Fig. 1). This panel included the ZR-75-1 for which both BST-2 and LGALS3BP staining were positive, according to the fact that these proteins were immuno-precipitated from this particular cell line (7). The staining of biopsies was independently scored by two observers (S.J. and S.E.P., breast pathologist). Score was calculated as the core average of the product IxP, where I is the intensity of the staining $(0,1,2$ or 3$)$ and $P$ the percentage $(0-100 \%)$ of stained tumour cells (see Fig. 2 for illustration). Cases where there was disagreement
Table I. Clinical and biological features of the cohort of 249 patients.

\begin{tabular}{lc}
\hline Characteristics & Data \\
\hline Median age at diagnosis: year & 57.0 (Min: 29.0, Max 94.0) \\
Average tumour size: $\mathrm{cm}$ & 2.64
\end{tabular}

Histological grade: n (\%)

$\begin{array}{ll}\text { G1 } & 41(16.5) \\ \text { G2 } & 93(37.3) \\ \text { G3 } & 97(39.0) \\ \text { ND } & 18(7.2)\end{array}$

Lymph node Involvement: n (\%)

Positive

$128(51.4)$

Negative

$108(43.4)$

ND

$13(5.2)$

Estradiol receptor (ER): n (\%)

Positive

$189(75.9)$

Negative

ND

Progesterone receptor (PR): n (\%)

Positive

$153(61.4)$

Negative

$93(37.3)$

ND

3 (1.2)

HER2: n (\%)

Positive

$110(44.2)$

Negative

$25(10.0)$

ND

$114(45.8)$

Median follow-up: months

148.0

Local recurrences: $\mathrm{n}(\%)$

Distant recurrences: n (\%)

Breast cancer specific death: n (\%)

$68(27.3)$

ND, not documented.

between the observers were reviewed and consensus reached on a multiheaded microscope. Tumours were classified as 'low' when $\leq$ to the median and 'high' otherwise. Statistical analyses were carried on using Prism5 (Graph-Pad software).

Depending on technical issues (e.g. cores damaged or lost during process, quality of the tissue present in the cores) unbiased observation could only be performed for about 350 samples for each marker. To avoid any cohort bias, we chose to include in the statistical analysis only the samples for which observation could have been made for each of the three markers. When cross-referenced, averaged scores for each of the targets were validated for 249 tumours out of the 400 initially included. The details of clinical and biological features of this cohort is given in Table I. Overall, this cohort fits the known statistics of the pathology regarding the rate of expression biomarkers (10) or the survival rates (1), thus excluding bias from the cohort selection. Unfortunately, 


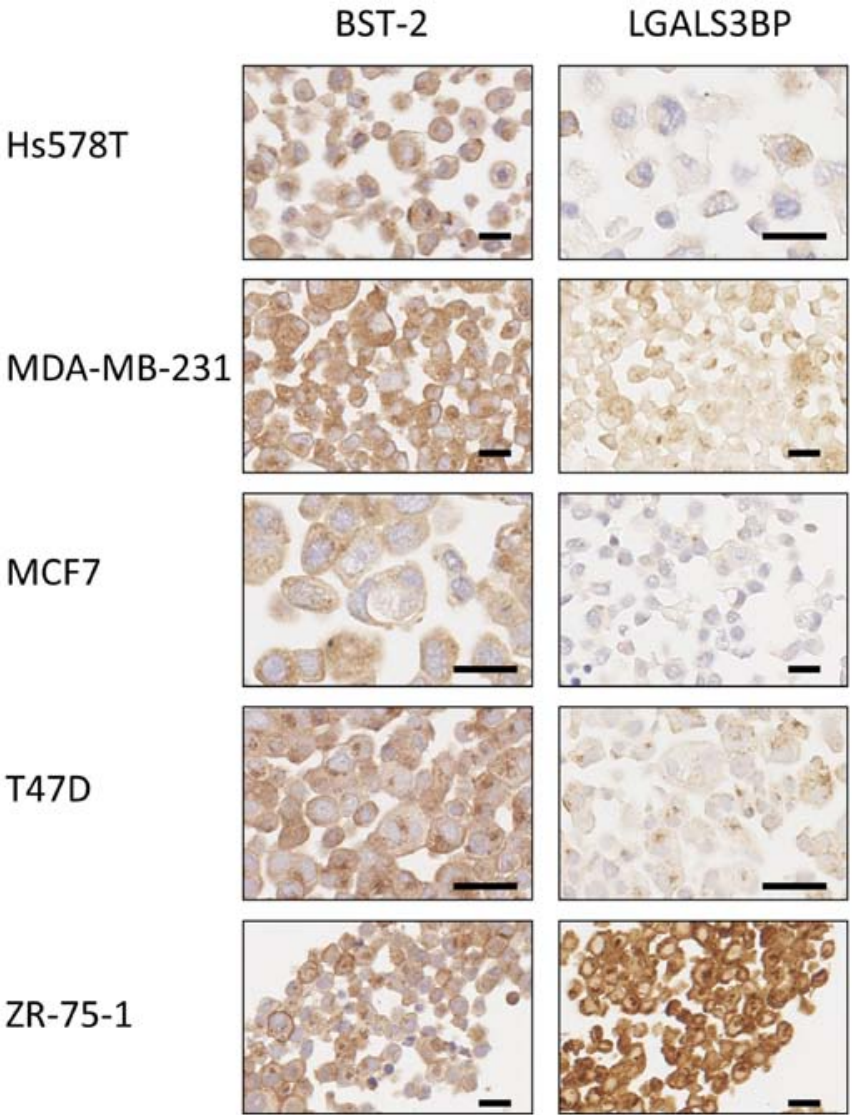

Figure 1. Immunohistochemistry performed on fixed paraffin-embedded cell pellets from various breast cancer cell lines. Anti-BST-2 and AntiLGALS3BP antibodies were used as described in Material and methods. BST-2 expression is observed in every cell line, albeit at various intensity, while LGALS3BP staining is more heterogeneous across the panel Bars: $50 \mu \mathrm{M}$.

HER 2 expression status was only available for 134 (53\%) of the samples rendering difficult to specifically address the triple-negative group (17 samples, 12.7\%) within this cohort. We thus decided to stratify our cohort based on the sole ER expression for subsequent analysis.

\section{Results}

Staining and scoring of biopsies. For all three antibodies, the observed staining was mainly cytoplasmic with membrane signal observable when the cells were strongly stained (Fig. 2). Variation of staining intensities allowed to classify each sample according to the level of expression of each marker (11). The frequency distributions of the scores were distinct when comparing the three markers (Fig. 3A) and quite different from the Gaussian-type frequency distribution commonly observed when measuring gene expression (Fig. 3B). Due to the asymmetrical score distributions, we chose to use median to discriminate between 'Low' and 'High' scores and compare group of tumours of the same size if possible. Median scores were 2.5 for $\mathrm{sLe}^{\mathrm{x}}$ and 200 for LGALS3BP. Median was also 200 for the BST-2 group, but the very homogeneous staining in this group resulted in 91 tumours being scored 200, making the use of the median inappropriate to split the series in two equal groups. After comparing the survival of the patients according

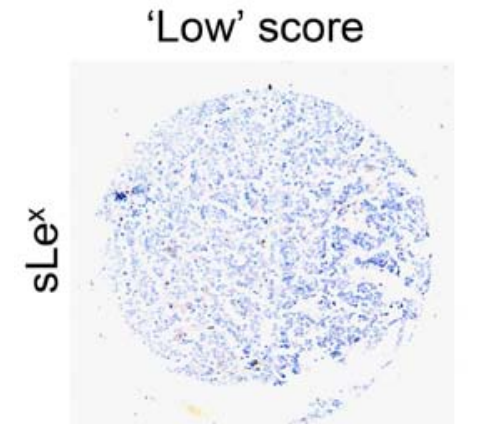

'High' score
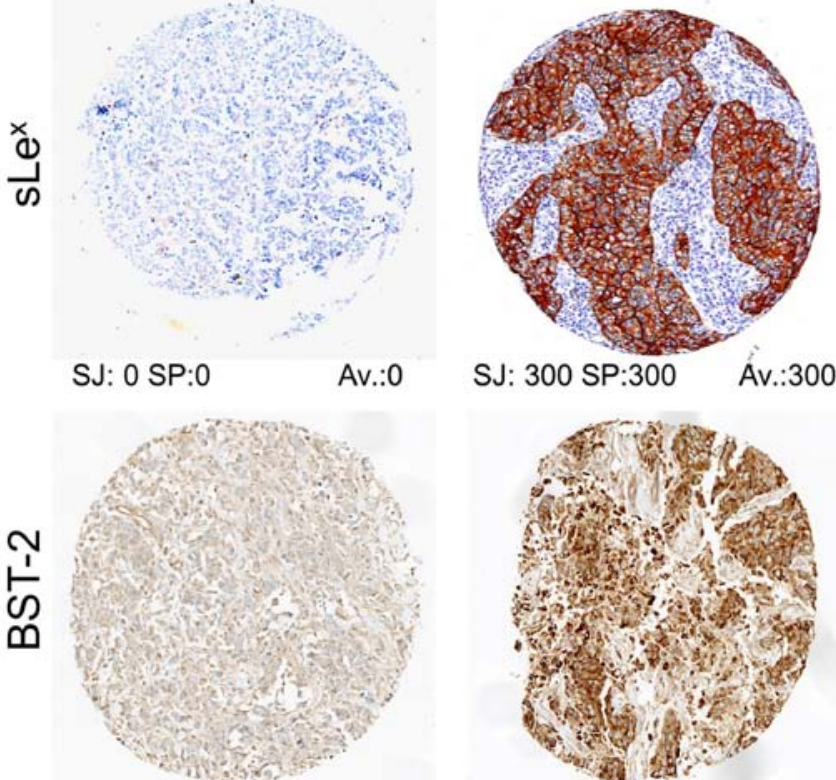

SJ: 100 SP:100

Av.:100
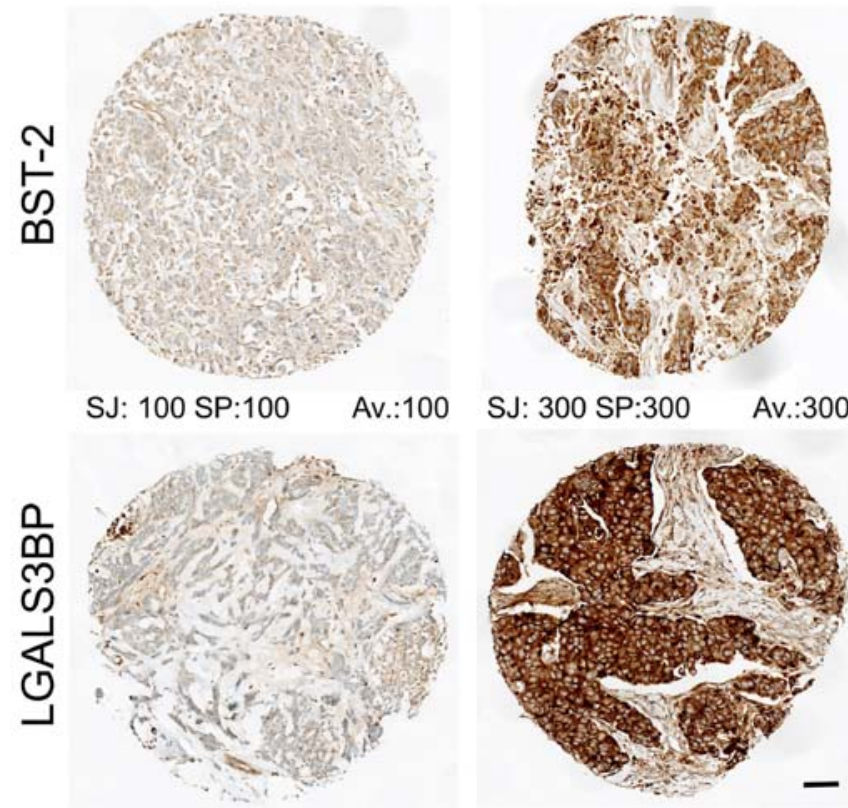

SJ: 300 SP:300 Av.:300

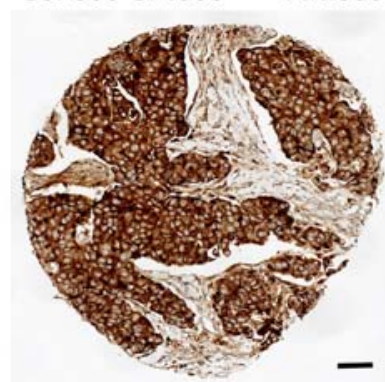

SJ: 70 SP:100

$A v .85$

SJ: 270 SP:300

Av.:285

Figure 2. Examples of Low and High staining obtained in TMA to illustrate the calculation of the score. Intensity of the staining was determined by cross-examination of all the cores stained for each given slide. Scores are calculated based on the percentage of tumour cells positively stained excluding the non-tumoural content of the core. Scores reported by both examiners (SJ and SP) are indicated for each sample together with their averages (Av.). Bar: $60 \mu \mathrm{M}$.

to the 25 and $75 \%$ percentile scores (Fig. 3C) we chose to use the highest quartile (score $>202.5$ ) to define our 'High' BST-2 group. Although we identified both proteins as carriers of $s \mathrm{Le}^{\mathrm{x}}$ in a breast cancer cell line (ZR-75-1), scores of $s L e^{x}$ did not significantly correlate with either BST-2 (Pearson $r^{2}=0.017$, $\mathrm{p}=0.042$ ) or LGALS3BP (Pearson $\mathrm{r}^{2}=0.002, \mathrm{p}=0.445$ ). This suggests that in breast tumours, the occurrence of the high expression of either carrier is independent of the occurrence of high $\mathrm{sLe}^{\mathrm{x}}$ expression and vice versa.

Correlation with clinical features. We first analysed the association of each of the three markers with several histological and clinical features of the tumours (Table II). As previously reported (12), $\mathrm{sLe}^{\mathrm{x}}$ high expression correlated with ER-negativity, lymph node (LN) involvement, and high grade. We also observed a correlation with progesterone receptor (PR) negativity. When considering the entire cohort, BST-2 and LGALS3BP did not correlate with any of the tested features. 
Table II. Correlation of antigen expression with biological features of the tumours.

\begin{tabular}{|c|c|c|c|c|c|c|c|c|c|c|c|c|c|c|c|}
\hline \multirow[b]{3}{*}{ Features } & \multicolumn{5}{|c|}{$s L e^{x}$} & \multicolumn{5}{|c|}{ BST-2 } & \multicolumn{5}{|c|}{ LGALS3BP } \\
\hline & \multicolumn{2}{|c|}{ Low $^{\mathrm{a}}$} & \multicolumn{2}{|c|}{ High } & \multirow[b]{2}{*}{ p-value } & \multicolumn{2}{|c|}{ Low } & \multicolumn{2}{|c|}{ High } & \multirow[b]{2}{*}{ p-value } & \multicolumn{2}{|c|}{ Low } & \multicolumn{2}{|c|}{ High } & \multirow[b]{2}{*}{ p-value } \\
\hline & $\mathrm{n}^{\mathrm{b}}$ & $\%^{\mathrm{c}}$ & $\mathrm{n}$ & $\%$ & & $\mathrm{n}$ & $\%$ & $\mathrm{n}$ & $\%$ & & $\mathrm{n}$ & $\%$ & $\mathrm{n}$ & $\%$ & \\
\hline \multicolumn{16}{|l|}{$\mathrm{ER}^{\mathrm{d}}$} \\
\hline Pos & 110 & 58.2 & 79 & 41.8 & 0.010 & 140 & 74.1 & 49 & 25.9 & NS & 102 & 54.0 & 87 & 46.0 & NS \\
\hline Neg & 22 & 38.6 & 35 & 61.4 & & 45 & 78.9 & 12 & 21.1 & & 33 & 57.9 & 24 & 42.1 & \\
\hline \multicolumn{16}{|l|}{$\mathrm{PR}^{\mathrm{d}}$} \\
\hline Pos & 92 & 60.1 & 61 & 39.9 & 0.012 & 111 & 72.5 & 42 & 27.5 & NS & 85 & 55.6 & 68 & 44.4 & NS \\
\hline Neg & 40 & 43.0 & 53 & 57.0 & & 74 & 79.6 & 19 & 20.4 & & 50 & 53.8 & 43 & 46.2 & \\
\hline \multicolumn{16}{|l|}{$\mathrm{HER}^{\mathrm{d}}{ }^{\mathrm{d}}$} \\
\hline Pos & 13 & 52.0 & 12 & 48.0 & NS & 17 & 68.0 & 8 & 32.0 & NS & 12 & 48.0 & 13 & 52.0 & NS \\
\hline $\mathrm{Neg}$ & 55 & 50.0 & 55 & 50.0 & & 81 & 73.6 & 29 & 26.4 & & 61 & 55.5 & 49 & 44.5 & \\
\hline \multicolumn{16}{|l|}{$\mathrm{LN}^{\mathrm{d}}$} \\
\hline Pos & 60 & 47.6 & 66 & 52.4 & 0.039 & 95 & 75.4 & 31 & 24.6 & NS & 71 & 56.3 & 55 & 43.7 & NS \\
\hline $\mathrm{Neg}$ & 71 & 61.2 & 45 & 38.8 & & 89 & 76.7 & 27 & 23.3 & & 59 & 50.9 & 57 & 49.1 & \\
\hline \multicolumn{16}{|l|}{$\mathrm{TS}^{\mathrm{d}}$} \\
\hline$<2 \mathrm{~cm}$ & 54 & 54.5 & 45 & 45.5 & NS & 69 & 69.7 & 30 & 30.3 & NS & 58 & 58.6 & 41 & 41.4 & NS \\
\hline$>2 \mathrm{~cm}$ & 78 & 53.1 & 69 & 46.9 & & 117 & 79.6 & 30 & 20.4 & & 77 & 52.4 & 70 & 47.6 & \\
\hline \multicolumn{16}{|l|}{$\mathrm{DM}^{\mathrm{d}}$} \\
\hline Pos & 34 & 46.6 & 39 & 53.4 & NS & 56 & 76.7 & 17 & 23.3 & NS & 41 & 56.2 & 32 & 43.8 & NS \\
\hline $\mathrm{Neg}$ & 100 & 56.8 & 76 & 43.2 & & 132 & 75.0 & 44 & 25.0 & & 96 & 54.5 & 80 & 45.5 & \\
\hline \multicolumn{16}{|l|}{ Grade $^{\mathrm{e}}$} \\
\hline 1 & 23 & 56.1 & 18 & 43.9 & $<0.001$ & 33 & 80.5 & 8 & 19.5 & NS & 25 & 61 & 16 & 39.0 & NS \\
\hline 2 & 61 & 65.6 & 32 & 34.4 & & 68 & 73.1 & 25 & 26.9 & & 50 & 53.8 & 43 & 46.2 & \\
\hline 3 & 36 & 37.1 & 61 & 62.9 & & 76 & 78.4 & 21 & 21.6 & & 51 & 52.6 & 46 & 47.4 & \\
\hline \multicolumn{16}{|l|}{$\mathrm{Age}^{\mathrm{e}}$} \\
\hline$<50$ yrs & 34 & 47.9 & 37 & 52.1 & NS & 49 & 69.0 & 22 & 31.0 & NS & 38 & 53.5 & 33 & 46.5 & NS \\
\hline $50-70$ yrs. & 72 & 57.6 & 53 & 42.4 & & 97 & 77.6 & 28 & 22.4 & & 69 & 55.2 & 56 & 44.8 & \\
\hline$>70$ yrs. & 28 & 52.8 & 25 & 47.2 & & 42 & 79.2 & 11 & 20.8 & & 30 & 56.6 & 23 & 43.4 & \\
\hline
\end{tabular}

${ }^{a}$ On the basis of median and quartile scores detailed in result section. ${ }^{b} \mathrm{n}$, number of tumours; ${ }^{c} \%$, percentages of tumours displaying Low or High levels of markers for each clinical feature considered. ${ }^{\mathrm{d} C}$ Correlation calculated using Fisher's exact test on Prism5 software. NS, not significant. ${ }^{\mathrm{e}}$ Correlation calculated using $\chi^{2}$ test on Prism5 software.

Both BST-2 and LGALS3BP high expression correlated with earlier time of metastasis and poor prognosis. Kaplan-Meier analyses were performed for each marker individually after ER stratification (Fig. 4). sLe ${ }^{\mathrm{x}}$ on its own did not associate with either distant metastasis-free survival (DMFS) or breast cancer specific survival (BCSS), as we have previously reported. However, strikingly, both BST-2 and LGALS3BP high expression predicted earlier development of distant metastasis and shorter patient survival in the ER-negative group, but not in the ER-positive subset of patients (Fig. 4). While none of the markers were associated with DM when analysing the cohort as a whole, both BST-2 and LGALS3BP correlated with DM within the ER-negative group $(\mathrm{p}=0.0270$ and $\mathrm{p}=0.0353$ Fisher's exact test, respectively). This suggests that both glycoproteins are involved in ER-negative tumour progression independently of $\mathrm{sLe}^{\mathrm{x}}$ expression.
BST-2 significantly alters the organotropism of ER-negative metastasis. We previously reported that 'very-high' (i.e. score of $>60$ ) expression of $\mathrm{sLe}^{\mathrm{x}}$ in ER-positive tumours drove metastasis to the bone (12). In the present study metastatic ER-positive tumours with very-high $\mathrm{sLe}^{\mathrm{x}}$ similarly colonised bone more frequently than those with low $\mathrm{sLe}^{\mathrm{x}}$ expression (87.5 and $52.6 \%$, respectively).

ER-negative tumours colonised distant organs at various frequencies: lung $(8.9 \%)$, liver $(12.5 \%)$, bone $(14.3 \%)$, brain (17.9\%) and other distant organs (23.2\%) such as distant lymph nodes (contra-lateral or mediastinal), pleura or skin. These frequencies were compared between groups displaying high or low expression of sLe ${ }^{\mathrm{x}}$, BST-2 and LGALS3BP (Fig. 5). Taken independently, variation in occurrence of metastasis for each site was not found to be significantly associated to the expression of any of the tested markers. However, high expression of 
A

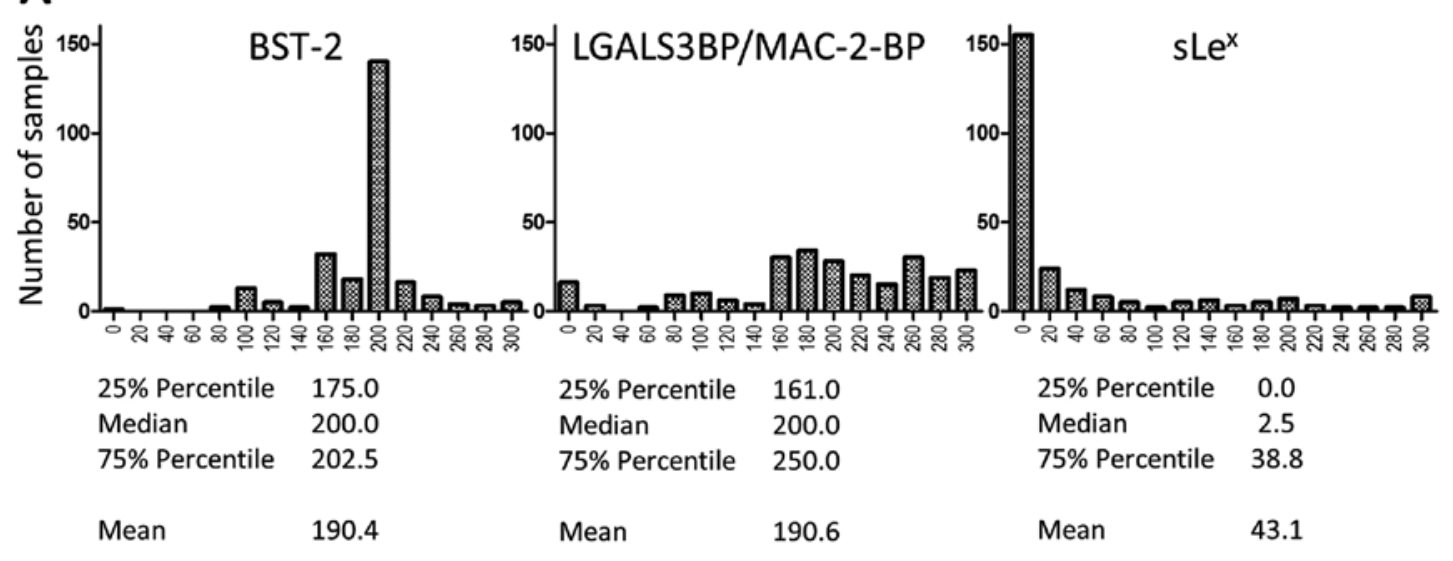

B

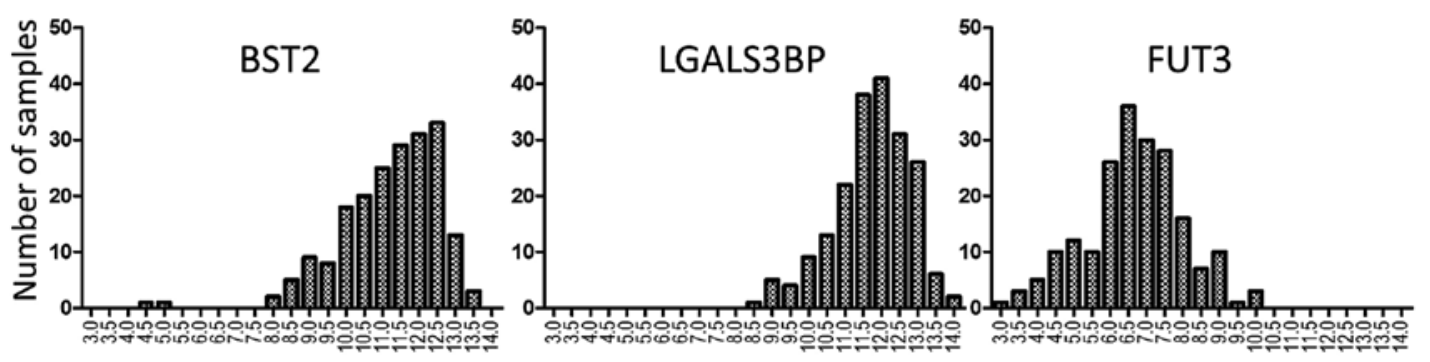

C ER-positive

ER-negative
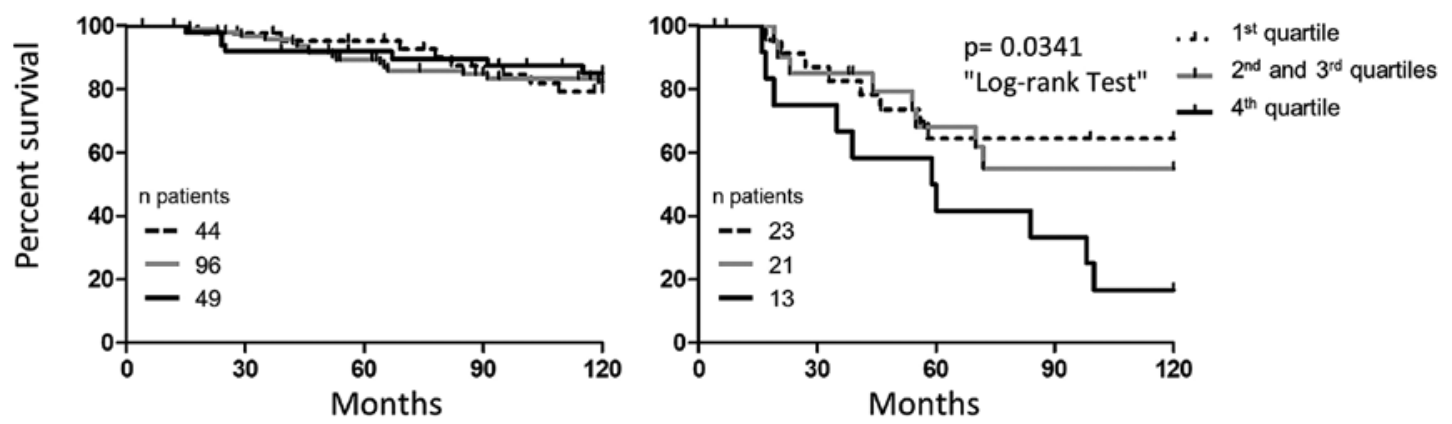

Figure 3. Score distribution and analysis. (A) Histograms showing the frequency distribution of the staining scores is non-symmetrical for LGALS3BP and sLex and clearly different for all three markers. Pecentile, median and mean are reported below each graph for each marker. (B) Histograms showing the frequency distribution of gene expression detected by RNA microarray. Data were generated by Desmedt et al (30) and show that the distribution of the signal measuring transcript levels are not distributed the same way than the staining scores. (C) Survival (breast cancer specific survival) analysis of patients according to the level of expression of BST-2 detected by immunostaining in ER-positive or ER-negative tumours. 1st quartile, 0-175; 2nd and 3rd quartiles, $>175$ to 202.5 ; 4th quartile, $>202.5$.

BST-2 seemed to generally affect the distribution of metastasis across the board. High expression of BST-2 was associated with increased metastasis in liver (2.8-fold) and brain (1.4-fold) while metastasis was decreased in lung (1.3-fold) and bone (1.9-fold). By comparison, the two other markers had limited effects. High $\mathrm{sLe}^{\mathrm{x}}$ expression seemed to follow the same trend as high BST-2, especially for liver and lung metastasis. High expression of LGALS3BP tended to be associated with an overall higher frequency of metastasis without affecting the tropism. As a result, we found that expression of BST-2 significantly altered the pattern of metastasis when compared to the two other markers (Chi-square test, $\mathrm{p}=0.0246$ ).

Combined expression of BST-2 and $s L e^{x}$ further improves BST-2 prognostic value. Although we did not find $\mathrm{sLe}^{\mathrm{x}}$ correlation with its carriers in tumours, there is, nonetheless, a discrete fraction of patients whose tumours displayed high $\mathrm{sLe}^{\mathrm{x}}$ expression together with high expression of BST-2 (10.6\% of patients) and/or LGALS3BP (24.4\%). Due to the documented function of $\mathrm{sLe}^{\mathrm{x}}$ carried by these proteins as E-selectin ligand $(7,8)$, we investigated the prognostic value of these combinations of markers in our series.

We analysed metastasis-free and breast cancer specific survival of patients within groups displaying high $\mathrm{sLe}^{\mathrm{x}}$ expression together with high expression of one or the other of its carriers (BST-2 or LGALS3BP) compared to the rest of the patients (Fig. 6).

This stratification did not bear any significance for the patients with ER-positive tumours. In the ER-negative group, the combination of $\mathrm{SLe}^{\mathrm{x}}$ with LGALS3BP did not improve, and 


\section{DMFS}

$s L e^{x}$

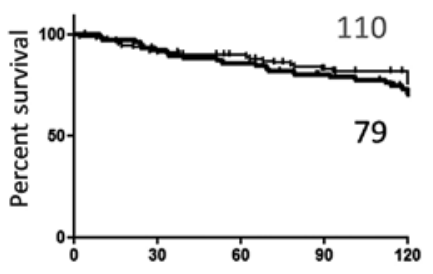

ER negative

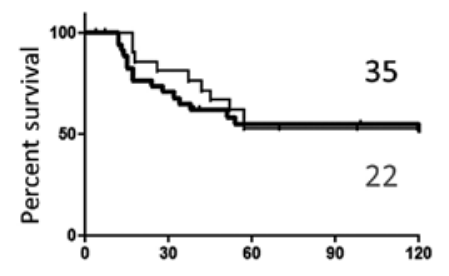

BCSS

ER positive
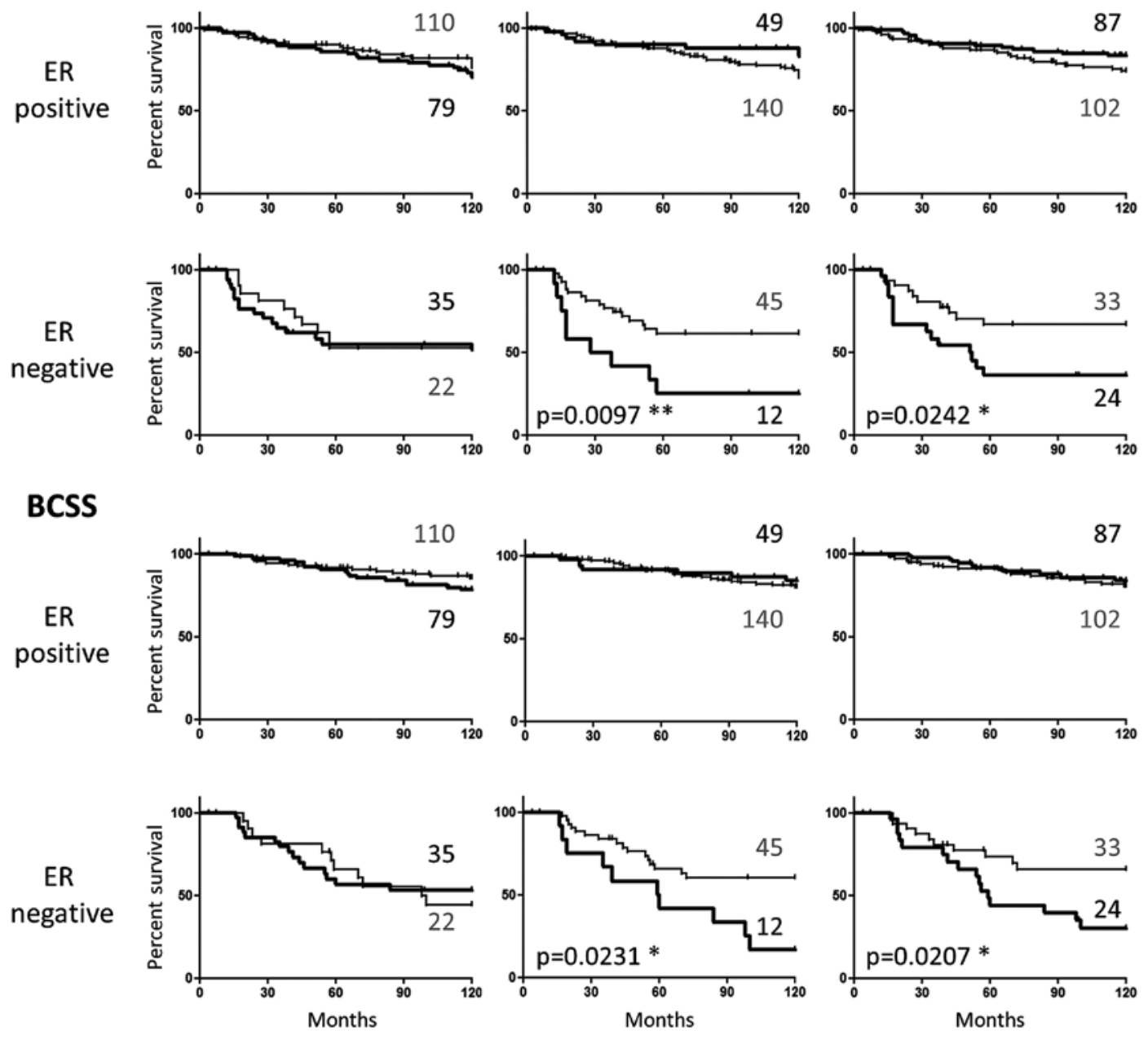

Low score

High score

Figure 4. Correlation of sLe ${ }^{\mathrm{x}}$, BST-2 and LGALS3BP expression with distant metastasis-free survival (DMFS) and breast cancer specific survival (BCSS) according to ER status. Number of patients included is indicated next to each DMFS curve. p-values were calculated using Grehan-Breslow-Wilcoxon test (Prism5).

actually reduced, the prognostic value of LGALS3BP. This suggests that the LGALS3BP function in ER-negative breast cancer metastasis is independent of $\mathrm{SLe}^{\mathrm{x}}$ expression. This was surprising since $\mathrm{SLe}^{\mathrm{x}}$ bearing LGALS3BP has been shown to be involved in the rolling of the ZR-75-1 breast cancer cell line on endothelial cells (8). However, LGALS3BP, as a secreted protein, has been linked to cancer metastasis through interactions with other proteins such as Tem1 (13) or galectins 1 and 3 (14-16). These multiple mechanisms may explain why LGALS3BP on its own bears some prognostic value, as previously reported (17), while the sLe ${ }^{\mathrm{x}} / \mathrm{LGALS} 3 \mathrm{BP}$ does not.

In contrast, the $\mathrm{sLe}^{\mathrm{x}} / \mathrm{BST}-2$ combination retained (and even increased) statistical significance in analysis for both metastasis and patient survival, despite the fact the sLe ${ }^{\mathrm{x}} / \mathrm{BST}-2$ group was reduced to 8 patients. Computation of Hazard Ratio showed an increase of risk when $\mathrm{SLe}^{\mathrm{x}}$ was combined to BST-2, for both BCSS (from 3.654 to 4.566) and DMFS (from 3.961 to 7.070 ), indicating that the patients displaying both markers concomitantly were more rapidly at risk than the others (Table III). By contrast, the same comparison performed using LGALS3BP with sLe ${ }^{\mathrm{x}}$ did not show any increase. The combi- nation of BST-2 with sLe ${ }^{x}$ identified a sub-group (14\%) of ER-negative patients with an $80 \%$ risk of metastasis at 5 years, twice the level in the patients with tumours not over-expressing both markers simultaneously. The patients with ER-negative carcinomas expressing both SLe $^{\mathrm{x}}$ and BST-2 had only a $20 \%$ survival at 10 years, about three times less than other patients with ER-negative cancers. This may be due to the metastatic tropism associated with BST-2, possibly enforced by $\mathrm{sLe}^{\mathrm{x}}$, since brain and liver metastasis are more rapidly lethal than bone and lung metastasis (18).

By comparison, stratification based on the high expression of both BST-2 and LGALS3BP did not result in a better prediction of metastasis or survival than each of the markers taken individually (Fig. 7).

Influence of treatment of ER-negative patients on survival analyses. Detailed review of the adjuvant therapy given to the ER-negative groups revealed that half of the patients (28) received chemotherapy drugs, while the other half (29) was only treated with Tamoxifen as it was routinely performed during the nineties (see Table IV for details). We found no 
Table III. Hazard ratios of survival according to single or combined variables.

\begin{tabular}{lccccc}
\hline & \multicolumn{2}{c}{ BCSS $^{\mathrm{a}}$} & & \multicolumn{2}{c}{ DMFS $^{\mathrm{b}}$} \\
\cline { 2 - 3 } Variables & Hazard ratio & 95\% Confidence interval & & Hazard ratio & 95\% Confidence interval \\
\hline BST-2 & 3.654 & $1.362-9.801$ & & 3.961 & $1.379-11.380$ \\
BST-2/sLe & 4.566 & $1.468-14.200$ & & 7.070 & $2.077-24.070$ \\
LGALS3BP & 2.541 & $1.153-5.597$ & & 2.554 & $1.130-5.772$ \\
LGALS3BP/sLe & 2.048 & $0.840-4.990$ & & 2.569 & $1.008-6.549$ \\
\hline
\end{tabular}

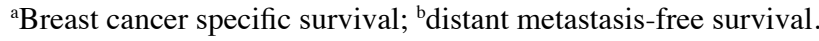
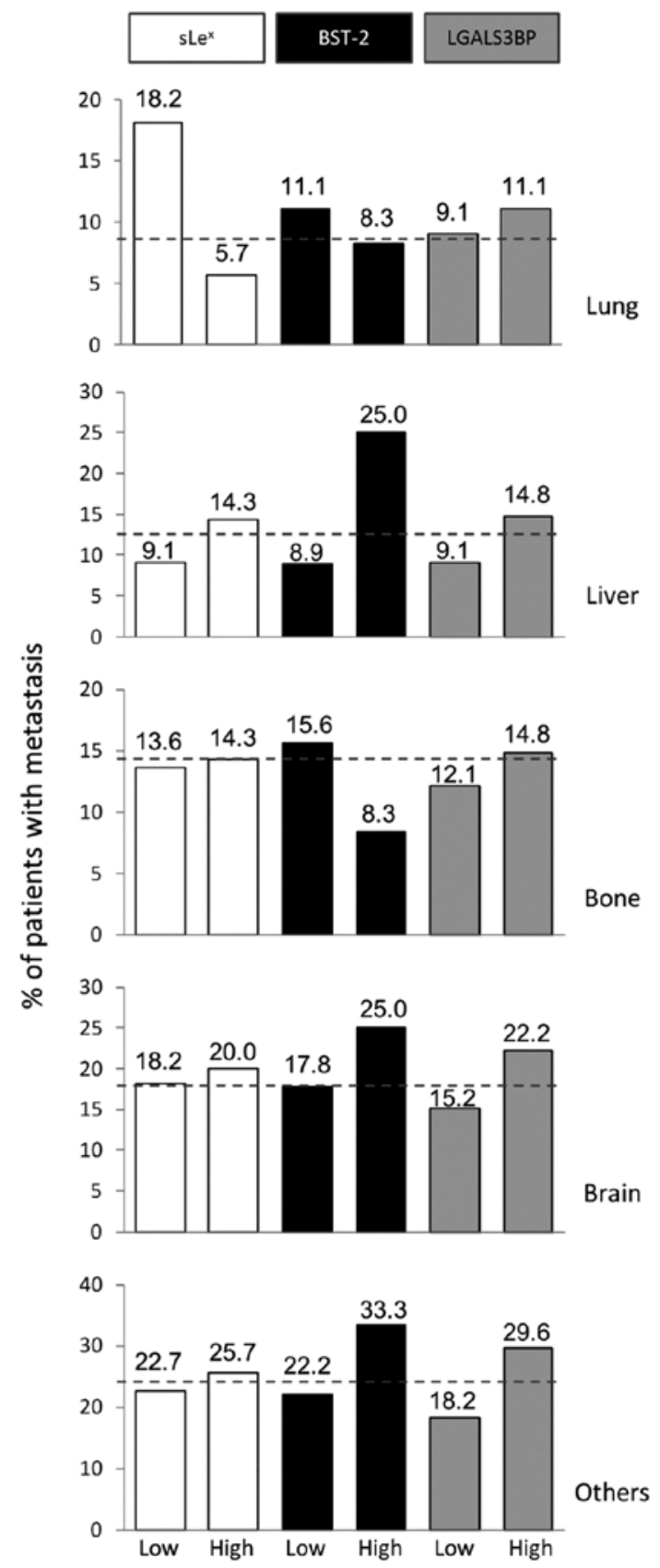

Figure 5. Organotropism of distant metastasis of ER-negative tumours according to high and low scores of sLe $\mathrm{e}^{\mathrm{x}}$ or its carriers. Frequencies of metastasis for each distant organ are indicated as \% on top of each column. Dotted lines on each graph represent the average frequency for patients with ER-negative tumours.
Table IV. Adjuvant treatments of ER-negative patients.

\begin{tabular}{llc}
\hline & \multicolumn{1}{c}{ Treatment } & No. of patients \\
\hline No chemotherapy & None & 1 \\
n=29 & Tamoxifen & 28 \\
Chemotherapy & CMF $^{\mathrm{a}}+$ Tamoxifen & 6 \\
$\mathrm{n}=28$ & $\mathrm{CMF}^{28}$ & 13 \\
& EFC $^{\mathrm{b}}$ & 5 \\
& Other chemotoxics $^{\mathrm{c}}$ & 4 \\
\hline
\end{tabular}

${ }^{\mathrm{a} C y c l o p h o s p h a m i d e, ~ m e t h o t r e x a t e, ~ 5-f l u o r o u r a c i l ; ~}{ }^{\mathrm{b}}$ Epirubicin, cisplatin, 5-fluorouracil; cincludes EFC + Tamoxifen (1), Taxol (1), methotrexate and mitozantrone (1) and cyclophosphamide + TAM.

differences in DMFS or BCSS when comparing these two arms, thus excluding any treatment bias in the results reported above. We further explored the effect of each protocol (no chemotherapy vs. chemotherapy) on the aggressive High BST-2/sLe ${ }^{\mathrm{x}}$ sub-population. The results seemed to indicate that the patients belonging to the poor prognosis group fared better when treated with chemotherapy compared to those treated only with Tamoxifen (Fig. 8). Albeit statistically significant, this analysis was performed with a very limited number of samples and should be considered with appropriate reserve.

\section{Discussion}

In this study, we retrospectively assessed the prognostic significance of two membrane bound glycoproteins, BST-2 and LGALS3BP, in breast cancer metastasis and survival. Both proteins were chosen based on the fact that they were found to be E-selectin ligands, when carrying the carbohydrate determinant known as sialyl-Lewis $\mathrm{x}\left(\mathrm{sLe}^{\mathrm{x}}\right)$ antigen, and potentially involved in blood borne metastasis. We previously investigated the expression of $\mathrm{sLe}^{\mathrm{x}}$ in breast cancer and found this glycan overexpressed in ER-negative breast cancers (7). To detect sLe ${ }^{\mathrm{x}}$ expression we chose the widely used HECA-452 monoclonal antibody that, in our hands, was able to recognize $s L e^{x}$ carried by multiple glycoproteins and/or glycolipids (7). HECA-452 binding is therefore non-discriminative of the carrier of the glycan. This is why we wanted to examine the relevance of $\mathrm{SLe}^{\mathrm{x}}$ together with two of its described protein carriers in our 
A

DMFS

ER positive

ER negative

B

\section{BCSS}

ER positive
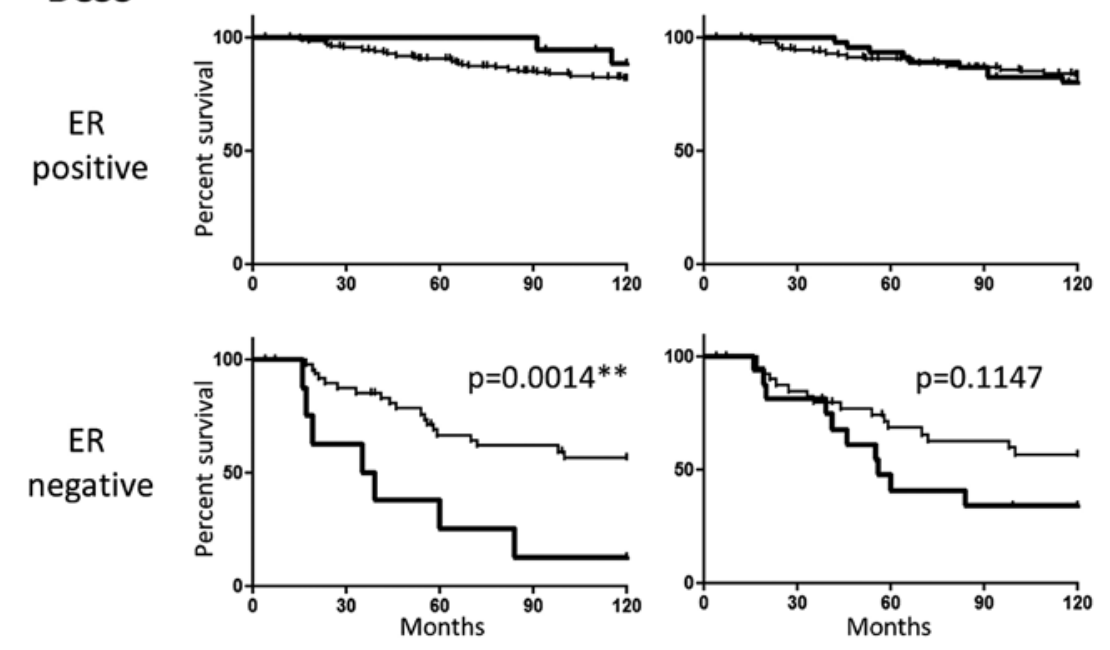

$\longrightarrow$ Others
LGALS3BP/sLe
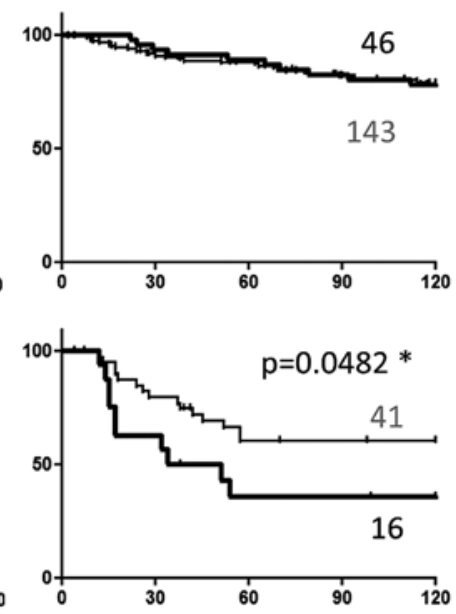

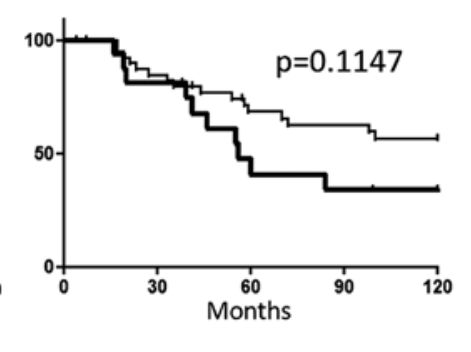

High carrier + High sLe

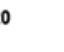

Figure 6. Correlation of combined expression of sLex with its carriers (BST-2 or LGALS3BP) with distant metastasis-free survival (DMFS) and breast cancer specific survival (BCSS) according to ER status (positive or negative). Number of patients included is indicated next to each DMFS curve. p-values were calculated using Grehan-Breslow-Wilcoxon test (Prism5).

statistical analyses. Since carbohydrate structures, or glycans, result from the combined expression of several synthesizing enzymes (glycosyltransferases), one of the most efficient way to assess their expression in tumour sample is to use specific probes (monoclonal antibodies or lectins) to detect them on tissue sections. Thus, to analyse both proteins and glycans from the same material, we chose to assess the expression of $\mathrm{sLe}^{\mathrm{x}}$ and its putative carriers by immunohistochemistry. Another aim of our study was to investigate the possible correlation of our markers or combinations of markers with the organotropism of the metastases. To achieve this, we exploited a series of formalin-fixed paraffin-embedded samples archived by the King's Health Partners Cancer Biobank, which consist of 400 patient biopsies all associated with the extensive clinical history (e.g. date and site of metastasis and treatment protocols) of the corresponding patients. From this series, we managed to validate scoring for all three markers for 249 samples. Although this cohort was of modest size, the quality of the associated clinical data made it suitable for the purpose of our study.

Of note, we found that both BST-2 and LGALS3BP glycoproteins were indeed associated with the development of subsequent distant metastasis and also patient survival, albeit only in the patients with ER-negative tumours. Conversely, the expression of these proteins was not dependent on the ER-status of the tumours. This suggests that both proteins act on the pathway of metastasis in partnership with other factors that are potentially specific to ER-negative cancer cells.

One such factor could be the sLe ${ }^{\mathrm{x}}$ antigen, which correlates with ER negativity (7). We found that combining $\mathrm{SLe}^{\mathrm{x}}$ and LGALS3BP high expression to stratify patients did not improve the prognostic significance of LGALS3BP. This suggests that the pro-metastatic function of LGALS3BP is not primarily due the ability of this protein to be recognised by E-selectin. Indeed, LGALS3BP (MAC-2BP) was experimentally shown to be involved in pro-metastatic interactions $(15,16)$ 

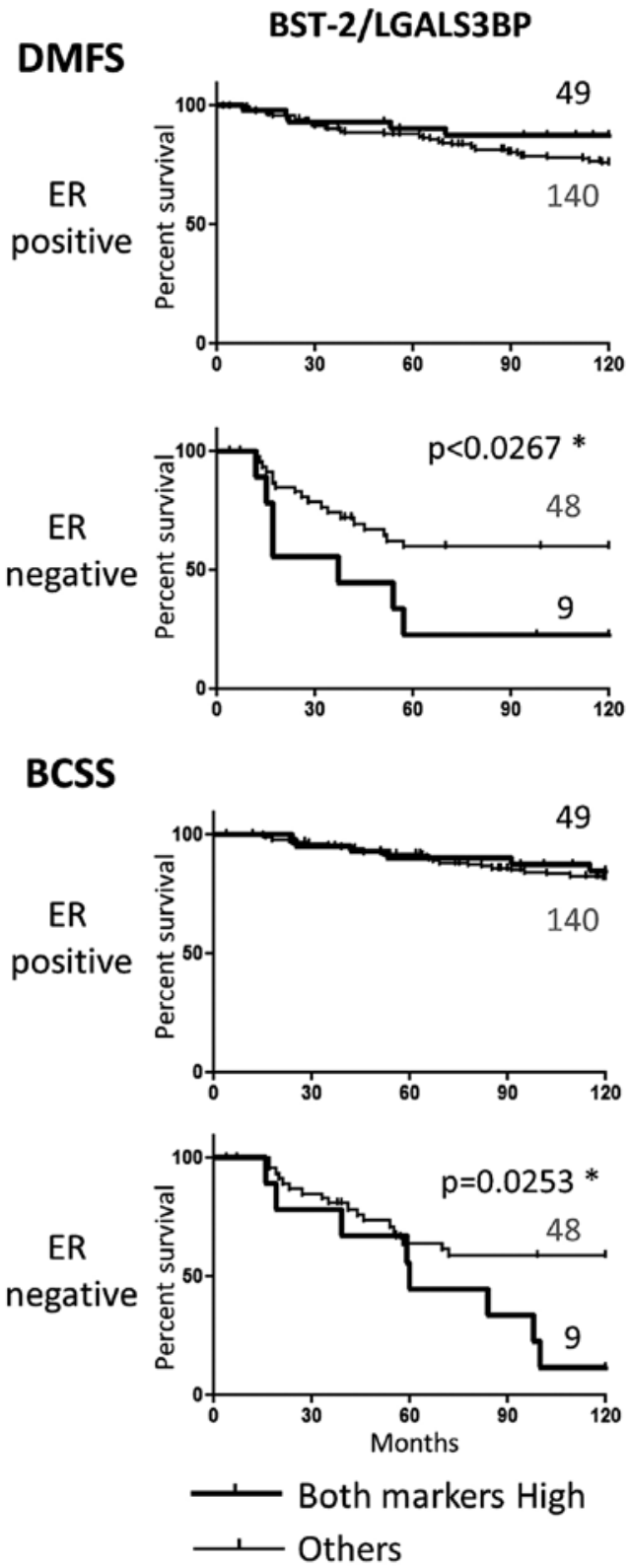

Figure 7. Correlation of combined BST-2/LGALS3BP expression with distant metastasis-free survival (DMFS) and breast cancer-specific survival (BCSS) according to ER status. Number of patients included is indicated next to each DMFS curve. p-values were calculated using Grehan-Breslow-Wilcoxon test (Prism5).

independently of $\mathrm{SLe}^{\mathrm{x}}$ expression or selectin involvement. One previous study also reported LGALS3BP to be associated with poor survival in node-negative breast cancer patients (17). On the contrary, another large study showed no correlation of the cytosolic expression of LGALS3BP with prognosis in breast cancer (19). However, the authors of this study argued that the cytosolic, immature, form of LGALS3BP may not be appropriate to predict prognosis due to the possible lack of biological activity. While implication of LGALS3BP in tumour progression and metastasis is now well documented in a number of cancers, it is also clear that the galectins/galectin binding protein/ligand networks involved are intricate and plastic (20). The present study confirms the clinical relevance of LGALS3BP by showing its association with occurrence of metastasis in ER-negative
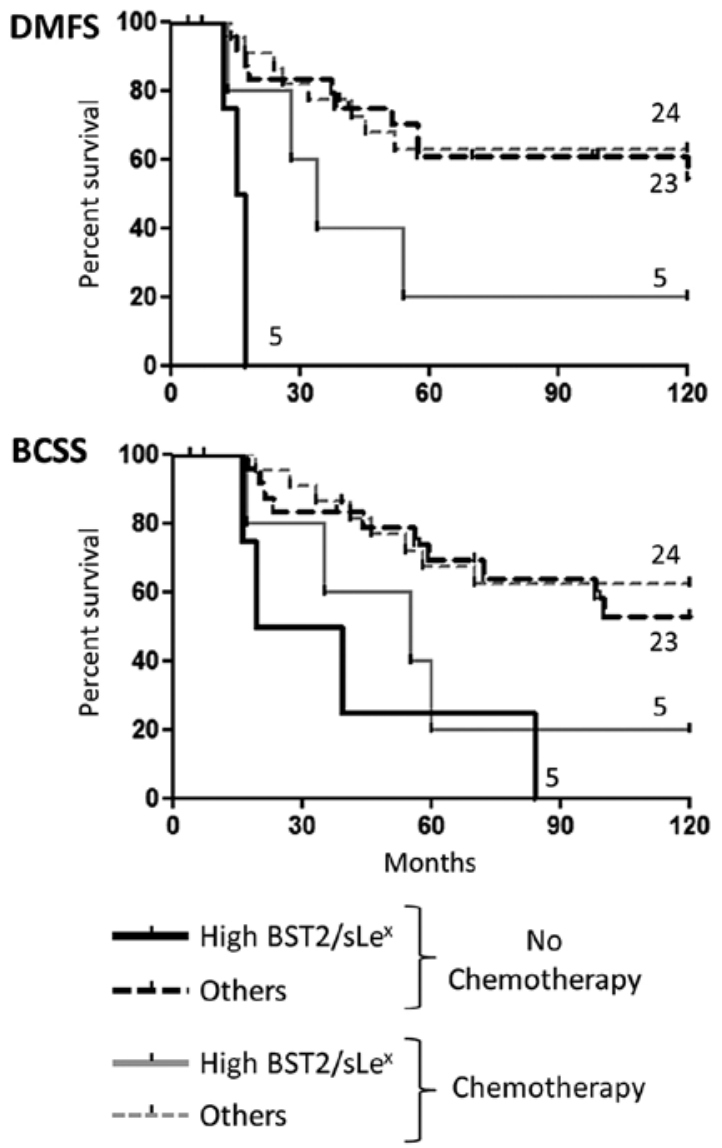

Figure 8. Effect of adjuvant treatment protocols (no chemotherapy/black lines vs. chemotherapy/grey lines) on distant metastasis-free survival (DMFS) and breast cancer-specific survival (BCSS) of ER-negative patients, according to combined BST-2/sLe ${ }^{x}$ high expression (Plain lines). Number of patients included is indicated next to each DMFS curve.

breast cancer, but dismisses $\mathrm{SLe}^{\mathrm{x}}$ antigen as a mediator of this effect.

On the contrary, high-sLe ${ }^{\mathrm{x}} / \mathrm{high}-\mathrm{BST}-2$ combined expression was a better predictor of distant metastasis and survival than BST-2 alone. High expression of BST-2 mRNA was previously associated with tumour aggressiveness and decreased survival in breast cancer by others (21). Cai et al also reported BST-2 protein expression to be associated with breast cancer bone metastasis in a smaller cohort $(n=50)$ of breast samples (22). Experimental data, based on cell lines and in vivo models, have hinted that BST-2 was involved in increased proliferation and reduced apoptosis (23), as well as increased migration, invasion and metastasis $(21,22,24)$. The data we are presenting imply that the role of BST-2 in metastasis is specific to patients with ER-negative tumours, and may be further enhanced by $\mathrm{sLe}^{\mathrm{x}}$ expression. The reason why BST-2 appears to specifically influence the tropism of ER-negative breast cancers is unclear. It could be related to the described function of BST-2 as an organiser of membrane microdomains (i.e. lipid rafts) (25). Indeed, by acting on the organization of the cell membrane, oligomers of BST-2 may promote the function of other molecules, specifically expressed in ER-negative cancer cells compared to ER-positive ones, which are involved in brain or liver metastasis. Identifying such partners of BST-2 
would thus warrant further investigations. Clusterisation of BST-2 around the lipid rafts would also create patches of BST-2 associated glycans, including sLe ${ }^{\mathrm{x}}(25)$. Such organization would indeed enhance the ability of BST-2 borne sLe ${ }^{x}$ to be recognised by selectin by improving the avidity of the interaction. Whether these putative mechanisms actually participate in the metastatic process in breast cancer would require further experimental demonstration.

The prognostic value of combined expression of BST-2 and LGALS3BP was not improved compared to each marker individually. Thus, the synergistic effect of sLe ${ }^{\mathrm{x}}$ and BST-2 expression on prognosis is specific of these particular two markers, and not random. Importantly, due to the complex biosynthesis of glycans, such a combination of markers could not have been easily detected using gene profiling strategies on its own. Supporting this, one very recent study has demonstrated that integrated analysis of glycosylation genes and their glycan products indeed resulted in significant prognostic data (26). In the same line, our present study demonstrates the potential of the widely available technique of immunohistochemistry to investigate combinations of glycans together with relevant protein carriers as prognosis markers.

The combination of BST-2 expression and sLe ${ }^{\mathrm{x}}$ positivity identified a small subset of patients that fared significantly worse than the other ER-negative breast cancer patients. Although sub-stratification ended up producing small groups of patients, the statistical analysis retained a high degree of significance. Whilst patients with ER-negative tumours may receive adjuvant chemotherapy, depending on other biological and patient variables, it is clear that not all of these women do equally badly (27). Based on new biomarkers, such as our BST-2/sLe ${ }^{\mathrm{x}}$ combination, one may therefore consider improving ER-negative patients follow-up and treatment protocols with possibly more aggressive therapy. On the other hand, such biomarkers, presumably involved in selectinmediated metastasis (28), could also serve as molecular target for tailored therapy (29). In that regard, we believe both BST-2 and LGALS3BP could be considered as putative targets to treat ER-negative metastatic breast cancer.

\section{Acknowledgements}

This work was supported by the Conseil Regional du Nord - Pas de Calais (SJ), La Ligue contre le Cancer (SJ and PD), Centre National de Recherche Scientifique (CNRS) through the Projet International de Coopération Scientifique (PICS) grant 'GLYCOMET' (PICS06165) (S.J., P.D., J.M.B.) and the Medical Research Council (V.T.).

\section{References}

1. Howlader N, Noone A, Krapcho M, et al: SEER Cancer Statistics Review. National Cancer Institute, 2011.

2. Chaffer CL and Weinberg RA: A perspective on cancer cell metastasis. Science 331: 1559-1564, 2011.

3. St Hill CA: Interactions between endothelial selectins and cancer cells regulate metastasis. Front Biosci (Landmark Ed) 16: 3233-3251, 2011.

4. Kawamura YI, Adachi Y, Curiel DT, Kawashima R, Kannagi R, Nishimoto N and Dohi T: Therapeutic adenoviral gene transfer of a glycosyltransferase for prevention of peritoneal dissemination and metastasis of gastric cancer. Cancer Gene Ther 21: 427-433, 2014.
5. Komatsu H, Mizuguchi S, Izumi N, Chung K, Hanada S, Inoue H, Suehiro $S$ and Nishiyama N: Sialyl Lewis $X$ as a predictor of skip N2 metastasis in clinical stage IA non-small cell lung cancer. World J Surg Oncol 11: 309, 2013.

6. Gakhar G, Navarro VN, Jurish M, Lee GY, Tagawa ST, Akhtar NH, Seandel M, Geng Y, Liu H, Bander NH, et al: Circulating tumor cells from prostate cancer patients interact with E-selectin under physiologic blood flow. PLoS One 8: e85143, 2013

7. Julien S, Ivetic A, Grigoriadis A, QiZe D, Burford B, Sproviero D, Picco G, Gillett C, Papp SL, Schaffer L, et al: Selectin ligand sialyl-Lewis $\mathrm{x}$ antigen drives metastasis of hormone-dependent breast cancers. Cancer Res 71: 7683-7693, 2011.

8. Shirure VS, Reynolds NM and Burdick MM: Mac-2 binding protein is a novel E-selectin ligand expressed by breast cancer cells. PLoS One 7: e44529, 2012.

9. Crother TR, Schröder NWJ, Karlin J, Chen S, Shimada K, Slepenkin A, Alsabeh R, Peterson E and Arditi M: Chlamydia pneumoniae infection induced allergic airway sensitization is controlled by regulatory T-cells and plasmacy toid dendritic cells. PLoS One 6: e20784, 2011.

10. Patani N, Martin L-A and Dowsett M: Biomarkers for the clinical management of breast cancer: International perspective. Int J Cancer 133: 1-13, 2013.

11. Pinder SE, Brown JP, Gillett C, Purdie CA, Speirs V, Thompson AM and Shaaban AM; Translational Subgroup of the NCRI Breast Clinical Studies Group: The manufacture and assessment of tissue microarrays: Suggestions and criteria for analysis, with breast cancer as an example. J Clin Pathol 66: 169-177, 2013.

12. Julien S, Ivetic A, Grigoriadis A, QiZe D, Burford B, Sproviero D, Picco G, Gillett C, Papp SL, Schaffer L, et al: Selectin ligand sialyl-Lewis $\mathrm{x}$ antigen drives metastasis of hormone-dependent breast cancers. Cancer Res 71: 7683-7693, 2011.

13. Becker R, Lenter MC, Vollkommer T, Boos AM, Pfaff D, Augustin HG and Christian S: Tumor stroma marker endosialin (Tem1) is a binding partner of metastasis-related protein Mac-2 BP/90K. FASEB J 22: 3059-3067, 2008.

14. Tinari N, Kuwabara I, Huflejt ME, Shen PF, Iacobelli S and Liu FT: Glycoprotein 90K/MAC-2BP interacts with galectin-1 and mediates galectin-1-induced cell aggregation. Int J Cancer 91: 167-172, 2001.

15. Piccolo E, Tinari N, Semeraro D, Traini S, Fichera I, Cumashi A, La Sorda R, Spinella F, Bagnato A, Lattanzio R, et al: LGALS3BP, lectin galactoside-binding soluble 3 binding protein, induces vascular endothelial growth factor in human breast cancer cells and promotes angiogenesis. J Mol Med Berl 91: 83-94, 2013.

16. Inohara $\mathrm{H}$, Akahani $\mathrm{S}$, Koths $\mathrm{K}$ and Raz A: Interactions between galectin-3 and Mac-2-binding protein mediate cell-cell adhesion. Cancer Res 56: 4530-4534, 1996.

17. Tinari N, Lattanzio R, Querzoli P, Natoli C, Grassadonia A, Alberti S, Hubalek M, Reimer D, Nenci I, Bruzzi P, et al; Consorzio Interuniversitario Nazionale per la Bio-Oncologia (CINBO): High expression of $90 \mathrm{~K}$ (Mac-2 BP) is associated with poor survival in node-negative breast cancer patients not receiving adjuvant systemic therapies. Int J Cancer 124: 333-338, 2009.

18. Largillier R, Ferrero J-M, Doyen J, Barriere J, Namer M, Mari V, Courdi A, Hannoun-Levi JM, Ettore F, Birtwisle-Peyrottes I, et al: Prognostic factors in 1,038 women with metastatic breast cancer. Ann Oncol 19: 2012-2019, 2008.

19. Foekens JA, Klijn JG, Natoli C, van Putten WL, Di Stefano P, Look MP, Portengen H and Iacobelli S: Expression of tumorassociated 90K-antigen in human breast cancer: No correlation with prognosis and response to first-line therapy with tamoxifen. Int J Cancer 64: 130-134, 1995.

20. Grassadonia A, Tinari N, Iurisci I, Piccolo E, Cumashi A, Innominato P, D'Egidio M, Natoli C, Piantelli M and Iacobelli S: 90K (Mac-2 BP) and galectins in tumor progression and metastasis. Glycoconj J 19: 551-556, 2004.

21. Mahauad-Fernandez WD, DeMali KA, Olivier AK and Okeoma CM: Bone marrow stromal antigen 2 expressed in cancer cells promotes mammary tumor growth and metastasis. Breast Cancer Res 16: 493, 2014

22. Cai D, Cao J, Li Z, Zheng X, Yao Y, Li W and Yuan Z: Up-regulation of bone marrow stromal protein 2 (BST2) in breast cancer with bone metastasis. BMC Cancer 9: 102, 2009.

23. Sayeed A, Luciani-Torres G, Meng Z, Bennington JL, Moore DH and Dairkee SH: Aberrant regulation of the BST2 (Tetherin) promoter enhances cell proliferation and apoptosis evasion in high grade breast cancer cells. PLoS One 8: e67191, 2013. 
24. Yi EH, Yoo H, Noh KH, Han S, Lee H, Lee JK, Won C, Kim BH, $\mathrm{Kim} \mathrm{MH}$, Cho $\mathrm{CH}$, et al: BST-2 is a potential activator of invasion and migration in tamoxifen-resistant breast cancer cells. Biochem Biophys Res Commun 435: 685-690, 2013.

25. Billcliff PG, Rollason R, Prior I, Owen DM, Gaus K and Banting G: CD317/tetherin is an organiser of membrane microdomains. J Cell Sci 126: 1553-1564, 2013.

26. Milde-Langosch K, Schütze D, Oliveira-Ferrer L, Wikman H, Müller V, Lebok P, Pantel K, Schröder C, Witzel I and Schumacher U: Relevance of $\beta$ Gal- $\beta$ GalNAc-containing glycans and the enzymes involved in their synthesis for invasion and survival in breast cancer patients. Breast Cancer Res Treat 151: 515-528, 2015

27. Teschendorff AE and Caldas $\mathrm{C}$ : A robust classifier of high predictive value to identify good prognosis patients in ER-negative breast cancer. Breast Cancer Res 10: R73, 2008.
28. Stübke K, Wicklein D, Herich L, Schumacher U and Nehman N: Selectin-deficiency reduces the number of spontaneous metastases in a xenograft model of human breast cancer. Cancer Lett 321: 89-99, 2012.

29. Eccles SA, Aboagye EO, Ali S, Anderson AS, Armes J, Berditchevski F, Blaydes JP, Brennan K, Brown NJ, Bryant HE, et al: Critical research gaps and translational priorities for the successful prevention and treatment of breast cancer. Breast Cancer Res 15: R92, 2013.

30. Desmedt C, Piette F, Loi S, Wang Y, Lallemand F, Haibe-Kains B, Viale G, Delorenzi M, Zhang Y, D'Assignies MS, et al: Strong time dependence of the 76-gene prognostic signature for nodenegative breast cancer patients in the TRANSBIG multicenter independent validation series. Clin Cancer Res 13: 3207-3214, 2007. 